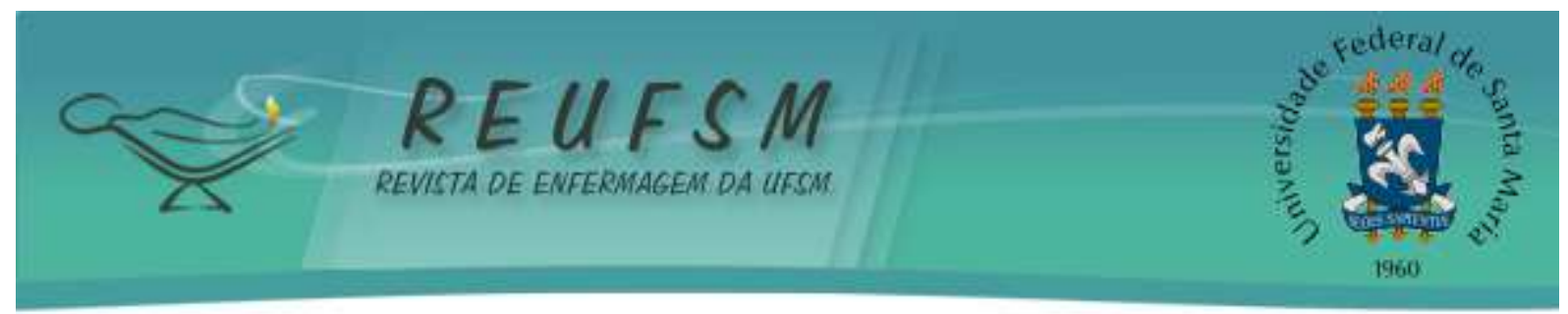

\title{
CRIANÇA HOSPITALIZADA: PERSPECTIVAS PARA O CUIDADO COMPARTILHADO ENTRE ENFERMAGEM E FAMÍLIA
}

\section{HOSPITALIZED CHILDREN: PERSPECTIVES FOR THE SHARED CARE BETWEEN NURSING AND FAMILY}

\section{NIÑOS HOSPITALIZADOS: PERSPECTIVAS PARA LA ATENCIÓN COMPARTIDA} ENTRE LA ENFERMERÍA Y LA FAMILIA

\author{
Juliane Portella Ribeiro ${ }^{1}$ \\ Giovana Calcagno Gomes ${ }^{2}$ \\ Maira Buss Thofehrn ${ }^{3}$ \\ Marina Soares Mota ${ }^{4}$ \\ Leticia Silveira Cardoso 5 \\ Susana Cecagno ${ }^{6}$
}

\section{Doi: $10.5902 / 2179769226333$}

RESUMO: Objetivo: analisar os aspectos que contribuem ou dificultam o cuidado compartilhado entre a família da criança hospitalizada e os profissionais de enfermagem. Método: estudo descritivo, exploratório, com abordagem qualitativa. Participaram 20 familiares de crianças hospitalizadas e 20 profissionais de enfermagem. A coleta de dados foi realizada através de entrevistas semiestruturadas. Os dados foram submetidos à Análise Temática. Resultados: a categoria Perspectivas para o cuidado compartilhado entre enfermagem e família constitui-se por: Aspectos que dificultam o cuidado compartilhado, destacando que o hospital limita as ações de cuidado dos familiares gerando-lhes sentimento de impotência; e Aspectos que contribuem para o cuidado compartilhado, ressaltando que compartilhar informações com o familiar propicia a sensação de respeito e valorização como coparticipante no cuidado. Conclusão: a família confere à enfermagem papel de referência e apoio, por essa razão a mesma encontra-se em lugar privilegiado para valorizar o protagonismo dos familiares e contribuir na efetivação do cuidado compartilhado.

Descritores: Cuidado da criança; Humanização da assistência; Pediatria; Criança hospitalizada; Enfermagem.

ABSTRACT: Aim: to analyze the contributing or hindering aspects to the shared care between the hospitalized children families and nursing professionals. Method: a descriptive and exploratory research with a qualitative approach. There were 20 hospitalized children

\footnotetext{
${ }^{1}$ Doutora em Enfermagem. Professora Adjunta da Faculdade de Enfermagem da Universidade Federal de Pelotas - UFPel, Pelotas, RS, Brasil. Email: ju_ribeiro1985@hotmail.com

2 Doutora em Filosofia. Professora Adjunta da Escola de Enfermagem da Universidade Federal do Rio Grande FURG, Rio Grande, RS, Brasil. Email: giovanacalcagno@ furg.br

${ }^{3}$ Doutora em Filosofia. Professora Adjunta da Faculdade de Enfermagem da Universidade Federal de Pelotas UFPel, Pelotas, RS, Brasil. Email: mairabusst@gmail.com

${ }^{4}$ Doutora em Enfermagem. Professora Adjunta da Escola de Enfermagem da Universidade Federal do Rio Grande - FURG, Rio Grande, RS, Brasil. Email: msm.mari.gro@gmail.com

${ }^{5}$ Doutora em Enfermagem. Professora Ajunta do Curso de Enfermagem da Universidade Federal do Pampa UNIPAMPA, Uruguaiana, RS, Brasil.Email: 1sc_enf@yahoo.com.br

${ }^{6}$ Doutoranda em Enfermagem. Programa de Pós-Graduação em Enfermagem da Universidade Federal de Pelotas - UFPel, Pelotas, RS, Brasil. Email: cecagno@gmail.com
} 


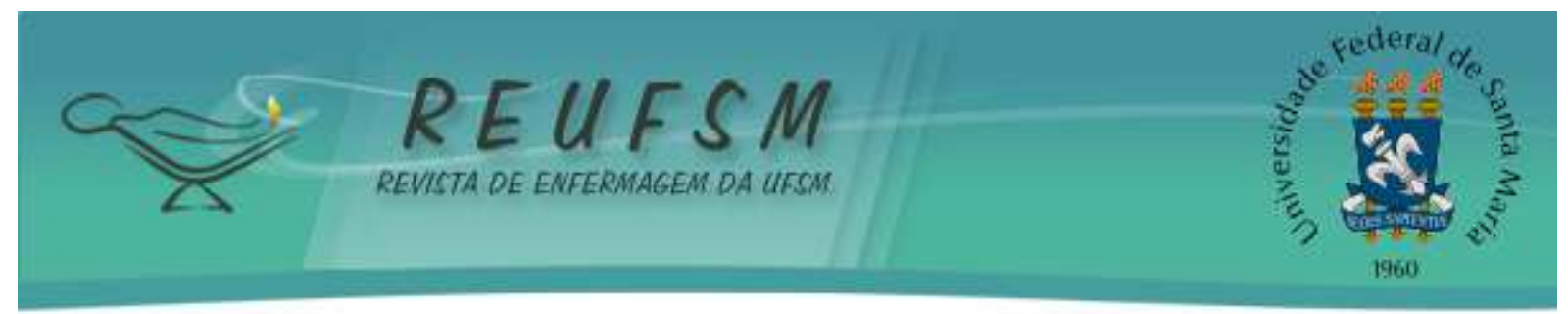

family members and 20 nursing professionals participating. The data were collected through semi-structured interviews. The data were submitted to thematic analysis. Results: The category "Perspectives for shared care between nursing and the family" has hindering aspects, once the hospital limits the care actions of the family members, which generates a feeling of impotence. However, this category also has contributing aspects, emphasizing that sharing information with the family provides respect and appreciation as a co-participant in care. Conclusion: The family concedes to nursing a role of reference and support. Thus, nursing is in a privileged place to value the protagonism of family members and contribute to the effectiveness of shared care.

Descriptors: Child care; Humanization of assistance; Pediatrics; Hospitalized Child; Nursing.

RESUMEN: Objetivo: analizar aspectos que contribuyen o dificultan el cuidado compartido entre la familia del niño hospitalizado y profesionales de enfermería. Método: estudio descriptivo, exploratorio, con enfoque cualitativo, en el cual participaron 20 familiares de niños hospitalizados y 20 profesionales de enfermería. La recolección de datos fue por medio de entrevistas semi-estructuradas. Los datos fueron sometidos al Análisis Temático. Resultados: la categoría Perspectivas para el cuidado compartido entre enfermería y familia es: Aspectos que dificultan cuidado compartido, donde el hospital limita las acciones de cuidado de familiares, generándoles sentimiento de impotencia; y Aspectos para el cuidado compartido, resaltando que compartir informaciones con el familiar genera respeto y valorización, propiciándole la sensación de coparticipante en el cuidado. Conclusión: la familia atribuye a la enfermería una posición de referencia y apoyo, por eso el profesional se encuentra en una posición privilegiada para valorizar el protagonismo de los familiares y contribuir en la efectuación del cuidado compartido.

Palabras claves: Cuidado del Niño; Humanización de laAsistencia; Pediatría; Niño Hospitalizado; Enfermería.

\section{INTRODUÇÃO}

No ambiente hospitalar, a presença do familiar se configura em uma referência da vida da criança fora do hospital, trata-se de alguém que ela conhece e reconhece o cheiro, o toque e a fisionomia ${ }^{1}$. No familiar a criança busca a força e a segurança necessária para enfrentar o medo, a dor e os demais sentimentos gerados em função da doença e da hospitalização. ${ }^{2}$

No entanto, na maioria das vezes, o familiar tem dificuldade em atender a essas necessidades, já que ele próprio não sabe como agir no ambiente hospitalar e enfrentar a doença da criança. Trata-se, portanto, de um momento estressante tanto para criança quanto para os seus familiares. Por essa razão, o foco do cuidado não deve ser exclusivo à criança, mas envolver a família, tornando-os parceiros ativos no processo de produção de saúde. ${ }^{3}$

Envolver a família nos cuidados à criança hospitalizada implica rever os modos como a enfermagem tem delineado esse processo, uma vez que a incongruência entre a participação 


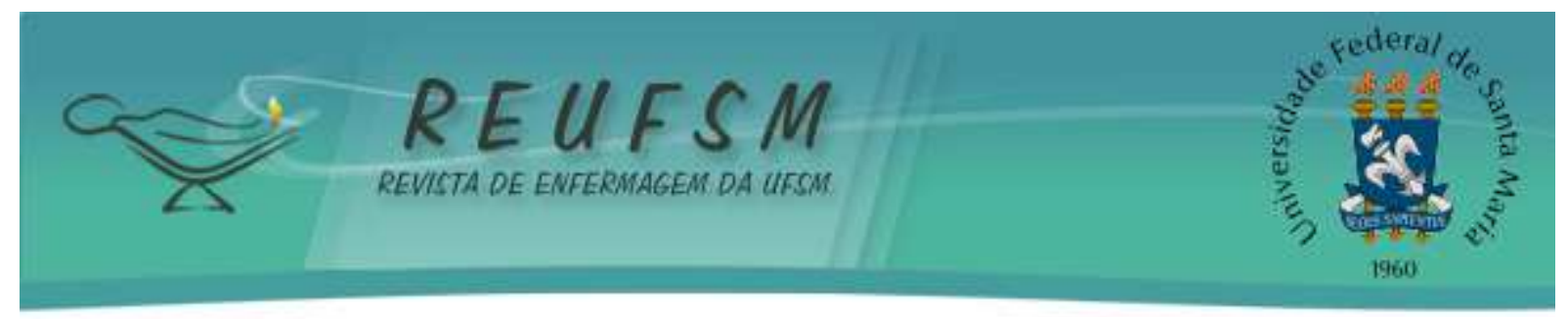

real e a participação desejada pelos mesmos pode causar dificuldades parentais. As enfermeiras pediátricas precisam lembrar que as preferências parentais para participação variam e precisam estar preparadas para apoiar a participação da família no nível em que seus membros escolhem, contribuindo para uma experiência satisfatória. ${ }^{4}$

Não raro, a família sente-se vulnerável no ambiente hospitalar, pois lhe são negados seu poder e direito de escolha, tendo de submeter-se a situações de conflito na relação com a equipe de saúde. Não ocorre um relacionamento autêntico de parceria, mas de desigualdade e distanciamento, em que a ausência de diálogo dá espaço para que a família se perceba desrespeitada e afastada de seu papel. Somam-se, ainda, sentimentos de frustração relacionados à falta de informação sobre procedimentos e tratamentos, desconhecimentos das regras e regulamentos hospitalares. ${ }^{5}$

Nesse sentido, autores apontam que o esclarecimento acerca do que as enfermeiras e a família consideram, respectivamente, como seus papéis no cuidado à criança hospitalizada é pré-requisito para a negociação. ${ }^{6}$ Dessa forma, o cuidado compartilhado implica no desenvolvimento de um projeto terapêutico que integre a família e a enfermagem, suscitando habilidades e capacidades de comunicação, diálogo, acolhimento de diversas demandas e oportunidades de exercitar-se como protagonista no cuidado. ${ }^{3}$

A literatura tem mostrado que o cuidado compartilhado está sendo construído e, por isso, ainda existem potenciais barreiras à sua negociação, incluindo a falta de comunicação e de informação, bem como experiências prévias de hospitalização e circunstâncias de vida da família $^{6}$. Logo, o cuidado compartilhado deve traduzir-se na construção de uma responsabilização compartilhada, em que enfermagem e família beneficiam a criança com sua especificidade, negociando ações estratégicas capazes de propiciar-lhe um cuidado integral e humanizado. ${ }^{1}$

Por essa razão, a questão de pesquisa deste estudo é: Quais aspectos contribuem ou dificultam o cuidado compartilhado entre a família da criança hospitalizada e os profissionais de enfermagem?

A resposta a tal questionamento poderá subsidiar a prática dos profissionais de enfermagem e auxiliar os mesmos na proposição de ações específicas e eficazes para obter-se o cuidado compartilhado autêntico, minimizando os efeitos negativos da hospitalização nas crianças e em seus familiares. Diante do exposto, a presente pesquisa teve como objetivo 


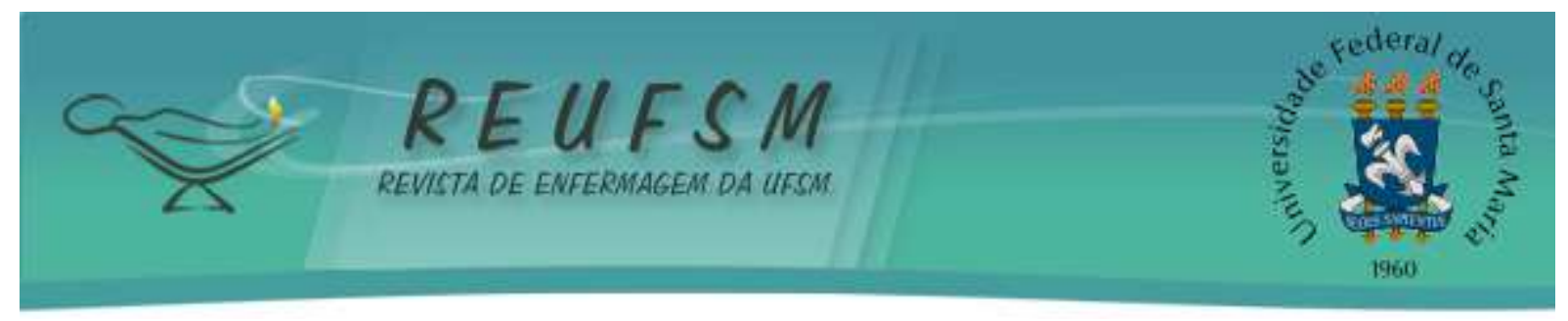

analisar os aspectos que contribuem ou dificultam o cuidado compartilhado entre a família da criança hospitalizada e os profissionais de enfermagem.

\section{MÉTODO}

Trata-se de um estudo descritivo e exploratório com abordagem qualitativa dos dados, vinculado a um projeto de pesquisa amplo, intitulado "A ambiência como ferramenta de humanização da unidade de pediatria”. Os cenários de estudo foram as unidades de pediatria de dois Hospitais Universitários do sul do Brasil.

Participaram do estudo familiares de crianças internadas e profissionais de enfermagem das unidades de pediatria. A seleção dos participantes foi intencional, de acordo com os critérios de inclusão e objetivos da pesquisa.

Para os familiares, os critérios de inclusão foram: ter idade mínima de 18 anos; ser familiar da criança hospitalizada, independente do diagnóstico; ser o cuidador principal e estar acompanhando a criança durante a internação. Foram excluídos do estudo familiares cuidadores eventuais da criança no hospital, ou seja, aqueles que não permanecem como acompanhantes da criança durante internação hospitalar.

Para os profissionais de enfermagem, os critérios de inclusão foram: ser enfermeiro, técnico ou auxiliar de enfermagem, atuante na unidade de pediatria há pelo menos seis meses. Foram excluídos do estudo profissionais de férias ou licença saúde no período da coleta dos dados.

Com vistas a garantir os princípios éticos relativos a pesquisas que envolvem seres humanos, os participantes foram incluídos no estudo, somente, após manifestarem sua concordância em participar do mesmo através da assinatura do Termo de Consentimento Livre e Esclarecido (TCLE). Além disso, o anonimato dos participantes foi preservado por meio do emprego da letra $\mathrm{F}$ para os familiares das crianças e da letra $\mathrm{E}$ para os profissionais de enfermagem, sucedidas do número da entrevista.

O número de participantes foi definido pela saturação dos dados definida quando, na avaliação do pesquisador, ocorre uma certa redundância ou repetição, não sendo considerado relevante persistir na coleta de dados. A coleta de dados ocorreu no segundo semestre de 2014, por meio de entrevistas semiestruturadas realizadas por um único entrevistador, uma vez que essa abordagem permitiu que o mesmo se colocasse o mais próximo possível da perspectiva do entrevistado, ${ }^{7}$ seguindo um roteiro com as seguintes questões: Quais aspectos você considera que 


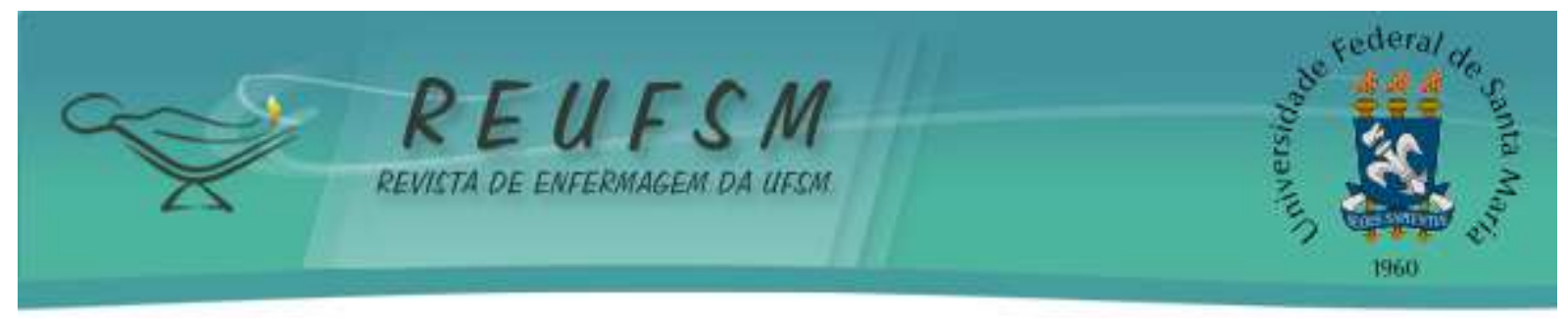

contribuem para que o cuidado à criança hospitalizada seja compartilhado entre a família e os profissionais de enfermagem? Quais aspectos você considera que dificultam para que o cuidado à criança hospitalizada seja compartilhado entre a família e os profissionais de enfermagem?

Com vistas à privacidade dos participantes, as entrevistas foram realizadas na sala de procedimentos da unidade, respeitando a disponibilidade do familiar cuidador e da referida sala, de forma a não interferir no atendimento à criança, tampouco no funcionamento da unidade. Para preservar o conteúdo original e aumentar a acurácia dos dados obtidos, as entrevistas foram capturadas por um gravador de áudio e, posteriormente, transcritas na íntegra.

Para a organização e tratamento dos dados, empregou-se o software Nvivo 10, programa que auxilia na análise de material qualitativo, com ferramentas de codificação e armazenamento de textos. ${ }^{8}$ Sendo, posteriormente, analisados e categorizados conforme a Análise Temática. ${ }^{9}$

Os preceitos éticos da realização de pesquisa envolvendo seres humanos, conforme a Resolução $\mathrm{n}^{\circ} 466$, de 12 de dezembro de 2012. ${ }^{10}$ O projeto foi encaminhado ao Comitê de Ética em Pesquisa e aprovado mediante o Certificado de Apresentação para Apreciação Ética (CAEE) no 31172914.6.0000.5324, Parecer nº 85/2014, em 15 de Julho de 2014.

\section{RESULTADOS E DISCUSSÃO}

A seguir, apresenta-se a caracterização dos participantes do estudo e a categoria "Perspectivas para o cuidado compartilhado entre enfermagem e família".

\section{Caracterização dos participantes do estudo}

Participaram deste estudo 20 familiares e 20 profissionais de enfermagem, totalizando 40 participantes. Os familiares caracterizaram-se exclusivamente por mulheres, com idades que variaram entre 19 e 48 anos, com predominância entre 19 e 29 anos (n=12;60\%). Destes, 19 eram mães da criança hospitalizada e uma era tia. Com relação ao estado civil, dez eram solteiras, sete casadas e três divorciadas. Dez possuíam grau de escolaridade correspondente ao ensino fundamental incompleto, quatro o ensino médio completo, três o ensino médio incompleto, duas com graduação de nível superior e uma com o primeiro grau completo. Doze possuíam atividade laboral e oito dedicam-se a atividades do lar.

Os profissionais de enfermagem caracterizaram-se predominantemente pelo sexo feminino, sendo 18 mulheres e dois homens, com idades que variaram entre 35 e 55 anos, a 


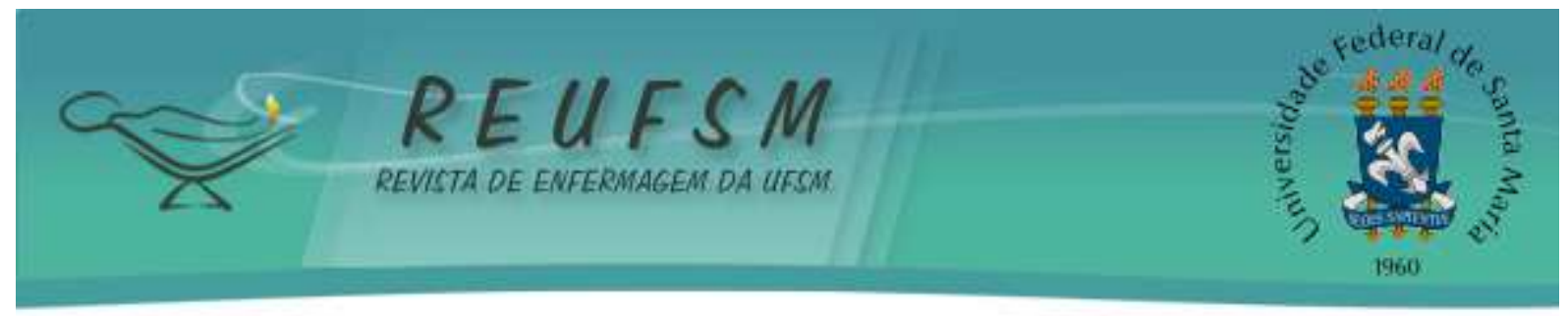

maioria entre 45 e 55 anos $(n=11 ; 55 \%)$. Destes, dez eram enfermeiros, cinco técnicos e cinco auxiliares de enfermagem cujo tempo de atuação na unidade de pediatria variou entre seis meses e 23 anos, com média de sete anos de atuação.

\section{Perspectivas para o cuidado compartilhado entre enfermagem e família}

A análise dos dados gerou a categoria "Perspectivas para o cuidado compartilhado entre enfermagem e família", a qual constitui-se por duas subcategorias: "Aspectos que dificultam o cuidado compartilhado" e "Aspectos que contribuem para o cuidado compartilhado".

\section{Aspectos que dificultam o cuidado compartilhado}

Os familiares apontaram que a hospitalização da criança suscita condutas e comportamentos diferentes aos anteriormente manifestados em casa, uma vez que a rotina hospitalar impõe restrições e normatizações, reduzindo a autonomia dos mesmos e gerandolhes o sentimento de impotência diante de ações comumente realizadas no âmbito domiciliar.

Na minha casa não é só eu que cuido. Meu marido ajuda a cuidar, mas aqui não. Aqui eles não deixam ficar dois. (F9)

Em casa tu dás banho a hora que tu queres, tu deitas onde tu queres, tu ficas de pé a hora que tu queres. Aqui não, aqui tu tens que depender das pessoas. (F7)

Estar no hospital é complicado. Tu não podes isso, não podes aquilo, então tem um monte de restrição. (F8)

De forma semelhante, pesquisa que investigou as estratégias utilizadas pela família para cuidar da criança no hospital apontou que, ao tentar adaptar-se e reproduzir os cuidados domiciliares, a família percebe que o ambiente hospitalar com normas, regras, profissionais, exames e procedimentos é muito diferente de sua casa, apresentando dificuldades em reproduzir até mesmo alguns cuidados simples, como o banho e a alimentação da criança. ${ }^{11}$

Os resultados deste estudo mostram que o nervosismo e o estresse dificultam a compreensão da família acerca da patologia e do tratamento e acarretam reações de choro, desmaio e mal-estar, que, por vezes, ganham maiores proporções do que quando manifestados por crianças.

Às vezes, os familiares estão mais nervosos que as próprias crianças. Aí acaba que a mãe chora, desmaia, pai que passa mal. (E6)

Geralmente o familiar tá numa situação de estresse, ele não sabe o que vai acontecer. Por mais simples que a gente saiba que é, para ele é muito complicado, então ele está muito estressado. (E3) 


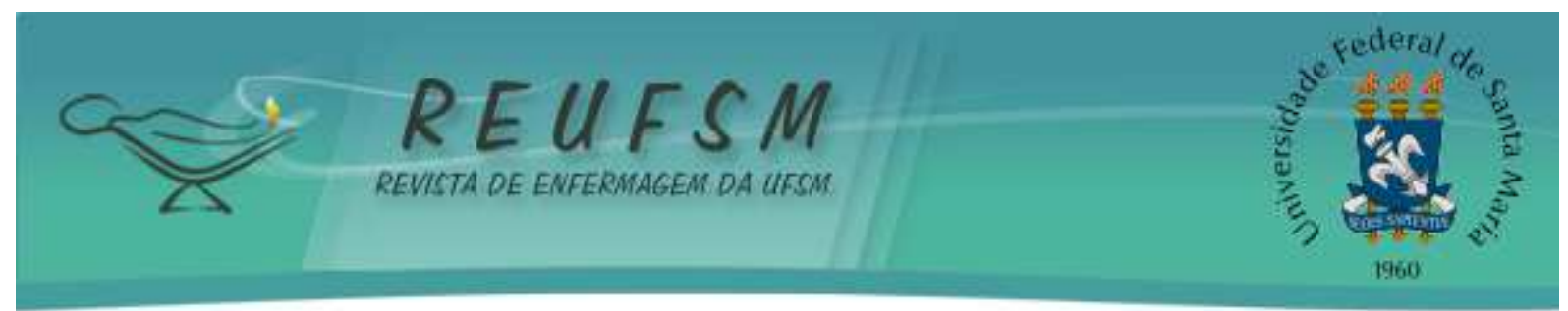

Autores assinalam que a família valoriza todos os aspectos relativos ao estado de saúde da criança e o conhecimento das implicações que a doença pode ter no seu futuro. À medida que os profissionais de saúde não têm clara tal valorização, reduz-se a possibilidade de resposta efetiva às suas necessidades, o que pode contribuir para aumentar a ansiedade e insegurança dos mesmos. ${ }^{2}$

\section{Aspectos que contribuem para o cuidado compartilhado}

As mudanças provocadas pela hospitalização na rotina e na relação familiar, muitas vezes, fazem com que a família estabeleça uma relação de proximidade e confiança com os profissionais, conferindo-lhes o papel de referência e apoio, sendo, inclusive, associados à figura familiar.

Aqui dentro, a gente não tem contato muito com a família porque só pode uma visita por dia [...] eu estou me dando superbem com os enfermeiros. Eu acho importante [essa relação] porque se tu precisas de um auxílio imediato, tu tens como socorrer a elas. (F6)

[...] da minha família eu não tenho apoio nenhum. Eu tenho mais apoio das enfermeiras, ou de pessoas que estão aqui no quarto, do que da minha família. (F2)

Elas são tipo família porque elas entram aqui e ficam à vontade com ele. Eu fico à vontade com elas. (F4)

Ao encontro desses achados, pesquisadores apontam que são as atitudes dos profissionais de enfermagem e de saúde que poderão criar um ambiente em que a família se sinta segura e fortalecida para enfrentar a hospitalização da criança. ${ }^{3}$ Logo, as ações de cuidado desenvolvidas na unidade de pediatria precisam ser planejadas também em torno da necessidade das famílias, de forma que a equipe de enfermagem constitua-se em fonte de apoio e de interação social. Ressaltase que a convivência entre profissionais e famílias influencia as atitudes e os comportamentos familiares, bem como a forma de significar o cuidado. ${ }^{12}$

Como forma de amenizar o sentimento de impotência gerado pelas restrições do ambiente hospitalar e conquistar maior autonomia no cuidado da criança, os familiares reivindicam um espaço de convivência. Local que disponibilize meios para que eles realizem atividades como lavar roupa, aquecer água, preparar e realizar as refeições, interagir com a criança e guardar pertences.

Se pudesse eu colocaria um lugar para lavar roupa, para pegar água quente. Um lugar para todo mundo usar. (F7) 


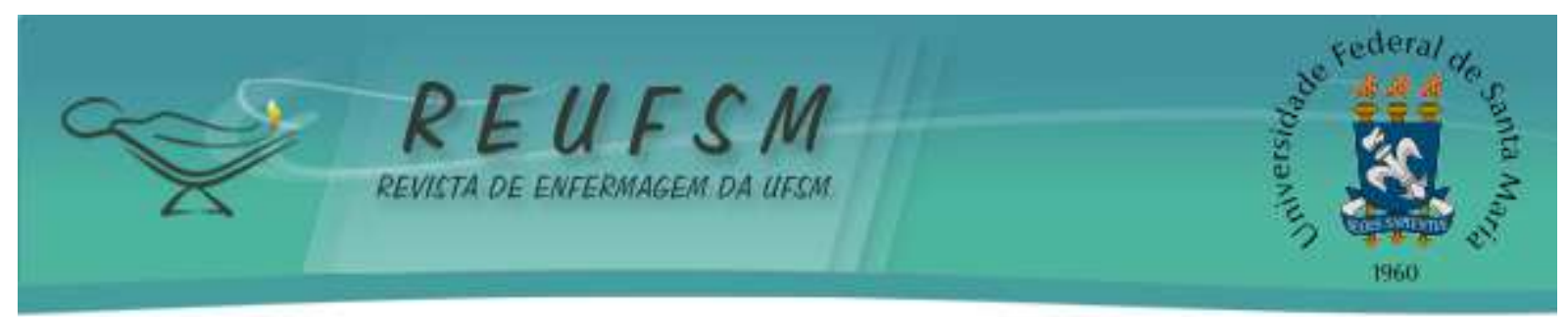

Que a gente tivesse um lugar mais digno de ficar com eles. Um espaço com uma mesinha, com cadeira decente, para fazer um almoço, uma janta, um lanche. (F8)

A respeito disso, pesquisa que analisou o envolvimento dos pais no cuidado da criança hospitalizada revelou que o ambiente hospitalar é considerado por eles desajustado às necessidades da criança e do respectivo acompanhante, especificamente, no que tange à infraestrutura hospitalar, às condições de alojamento, espaço e privacidade. ${ }^{2}$ Outra pesquisa que investigou as comodidades de sala pediátrica na perspectiva dos pais e crianças hospitalizadas na Polônia indicou que ambos prestam atenção às condições do ambiente em que o cuidado é ofertado. Os pais valorizam a qualidade das instalações e acomodações, enquanto as crianças valorizam as atividades disponíveis para eles realizarem em seus tempos livres. ${ }^{13}$

No presente estudo, os familiares também reivindicam atenção dos profissionais de saúde por meio da escuta, pois os mesmos percebem que não há valorização de seu conhecimento acerca da criança e das alterações observadas em sua saúde.

Eu acho assim, atenção mais pra mãe, para os pais, para conversar mais, porque às vezes assim tu vês que as mães e os pais falam e parece que eles não dão bola. (F8)

A gente só precisava que eles nos escutassem mais. Se eles nos escutassem mais, eles saberiam o que ele tem. Tá certo que tem que perguntar para a criança também porque só ele sabe o que ele está sentindo, mas acho que eles precisavam nos escutar mais. (F1)

Apesar de a equipe de enfermagem ser detentora de conhecimentos científicos específicos para o cuidado, é o familiar quem consegue captar as pequenas alterações na saúde da criança. Por essa razão, ele pode ser um grande colaborador no tratamento da criança oferecendo informações importantes que auxiliam no cuidado e que devem ser valorizadas pelo enfermeiro devido ao potencial para transformar e enriquecer o cuidado. ${ }^{14}$

Atenção reivindicada pelos familiares transcende a escuta, envolvendo uma relação de confiança e reciprocidade, que o cuidado compartilhado suscita, com a valorização do trabalhador de enfermagem e do familiar.

Acho que eles precisam da gente aqui para ajudar eles e a gente precisa deles para tratar do nosso filho. (F1)

Se eu tenho que fazer alguma coisa eu vou lá e pergunto, ouço as enfermeiras, eu gosto de saber das enfermeiras e do médico também, então é sempre junto. (F7) 


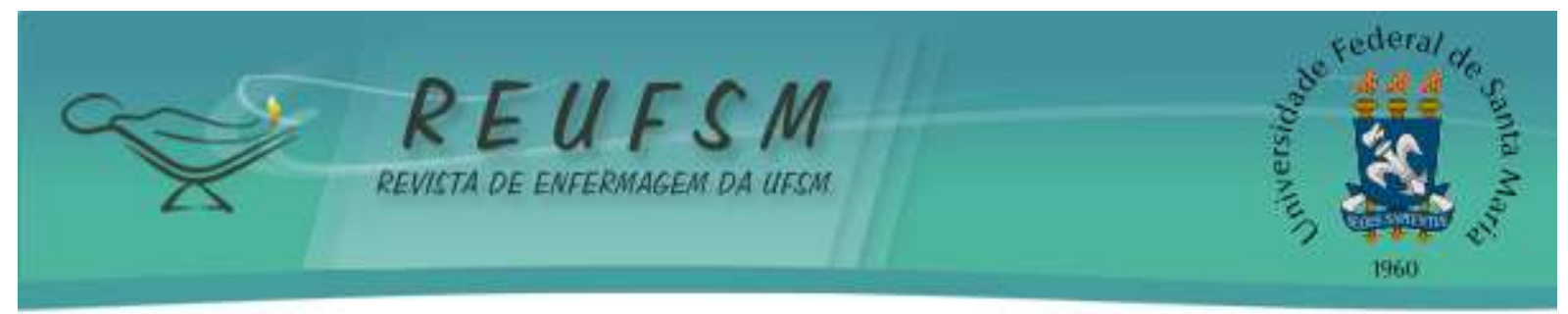

Estudo sobre o processo de comunicação entre pais de crianças hospitalizadas e seus enfermeiros apontou que ambos percebem como importante o respeito pela sua experiência quanto pela do outro, o qual pode ser expresso por meio de perguntas, escuta, explicações, verificação da compreensão e na negociação de papéis para a realização do cuidado à criança. ${ }^{15}$

Os profissionais advertem que informar sobre o tratamento, realização de procedimentos e exames, bem como esclarecer as dúvidas que emergem diante dos mesmos, além de transmitir maior segurança e tranquilidade aos familiares, caracteriza-se como uma atitude de respeito e valorização da participação do familiar no tratamento da criança.

A gente procura sempre informar a família. Esclarecer o que vai ser feito, como vai ser feito, que tipo de tratamento é, o que coletar, o que vai fazer de exames. Na medida do possível, se procura esclarecer a família para transmitir mais tranquilidade, mais segurança. (E2)

Conversa-se com a mãe, instrui a mãe a respeito do que vai ser feito, de que forma vai ser feito, quais os efeitos que poderão ter. Muitas vezes, ela nem tem o conhecimento adequado para discernir se é bom ou se é ruim, mas, assim ela se sente respeitada, se sente valorizada, se sente parte daquele tratamento, então isso que é primordial. (E6)

Ao encontro desse achado, pesquisa que investigou os significados atribuídos por familiares de crianças internadas na pediatria apontou que a família adquire confiança no cuidado profissional pelo fato de ser ouvida e ter suas considerações levadas em conta pelos profissionais. ${ }^{12}$

Muitas vezes, é por meio dessas interações entre enfermagem e família que se estabelece subsequentemente o acesso e interação com a criança.

Eu acho que quando se tem um bom diálogo com a mãe, explicar o que vai fazer, se ela faz alguma pergunta tu procura uma resposta, isso facilita o diálogo, é a maneira de chegar na criança. (E8)

Tu tens que conquistar o cuidador, conseguir vencer barreiras através desse cuidador, aí tu vai conseguir chegar ao paciente. (E6)

Considerando que a família se configura em intermediadora do cuidado infantil durante a hospitalização, estimular sua participação no processo de produção de saúde é fundamental, visto que sua ausência produz insegurança na criança, o que poderá implicar na criação de uma barreira entre a enfermagem e ela. ${ }^{13} \mathrm{~A}$ criança, por estar em processo de desenvolvimento, pode não ter a compreensão acerca da necessidade de realizar ações de autocuidado, portanto, é por meio do familiar que tais ações, de fato, são efetivadas.

Aqui a gente procura trazer a família para o autocuidado da criança. Orientar como é que cuida, como é que não cuida. (E2) 


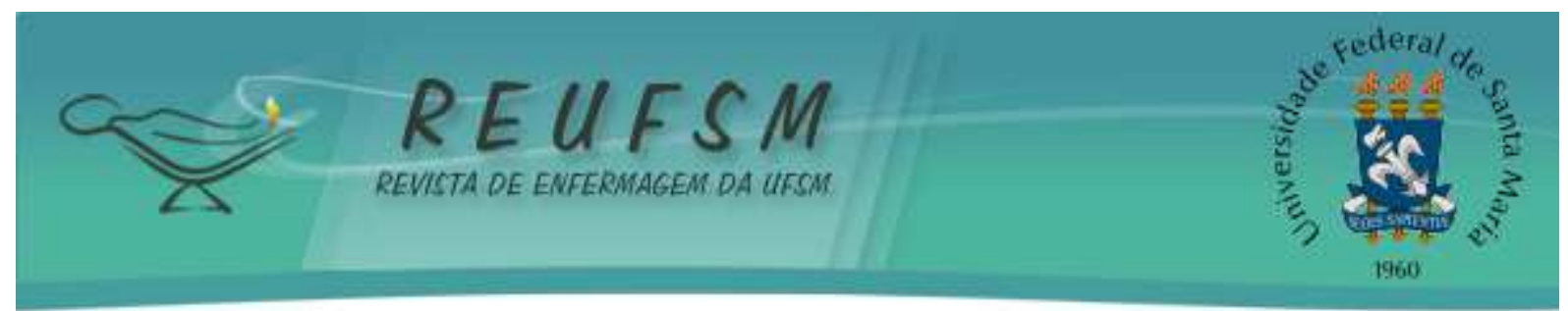

A criança não tem consciência que está doente, ela não sabe que está com um acesso no braço porque precisa fazer medicação. Com a criança tu tens que interagir através de outras pessoas, como o cuidador, para que seja efetivo o cuidado. (E6)

Pesquisa realizada com o objetivo de descrever a comunicação médico - paciente pediátrico - família mostrou que o familiar possui papel fundamental como mediador de informações, clarificando ou reiterando as mesmas, auxiliando, assim, a criança a compreender e aderir ao tratamento. ${ }^{16}$

Nesse sentido, os profissionais buscam aproximar o familiar para o desenvolvimento do cuidado compartilhado, de forma a prepará-lo para sua manutenção no âmbito domiciliar. Entretanto, eles salientam que há cuidados que são específicos à enfermagem e, por isso, o familiar não é convidado a participar.

[...] uma criança que vai com uma gastrostomia para casa a gente tem que passar esse cuidado para mãe, temos que habilitar ela a manusear a gastrostomia. Tem cuidados que são só nossos e tem outros que são compartilhados, por exemplo, o banho quem dá é a mãe, a não ser uma criança que está em respirador, aí nós fazemos, mas do contrário a mãe é convidada a participar. (E2)

Estudo com o objetivo de descrever as concepções da equipe de enfermagem acerca do familiar cuidador da criança hospitalizada evidenciou que ele nem sempre vai ter condições físicas e/ou emocionais para prestar o cuidado, dado que os próprios membros da equipe de enfermagem, providos de capacitação adequada, podem, por vezes, deparar-se com adversidades inerentes ao cuidado a ser prestado. Já, para o familiar que, de uma hora para a outra, assume o papel de responsável por aquela criança doente, tendo que aprender a realizar procedimentos para os quais nunca foi minimamente preparado, o cuidado torna-se um desafio. ${ }^{14}$

\section{CONSIDERAÇÕES FINAIS}

$\mathrm{O}$ presente estudo evidenciou que existem aspectos que dificultam o cuidado compartilhado, uma vez que o ambiente hospitalar exige da família condutas e comportamentos diferentes dos manifestados em casa, limitando suas ações de cuidado e, consequentemente, gerando-lhes sentimento de impotência. Nesse contexto, a proposta de incluir uma sala de convivência, ampliando o espaço para interação e coparticipação dos familiares no cuidado à 


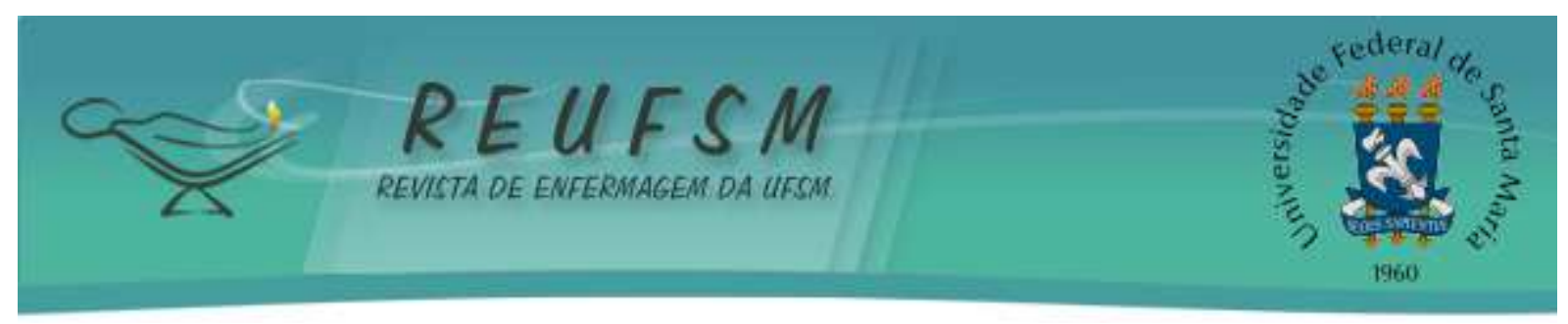

criança por meio da realização de atividades cotidianas, mostra-se positiva no sentido de amenizar tal sentimento e facilitar o cuidado compartilhado entre enfermagem e família.

Além disso, informar o familiar sobre o tratamento e a realização de procedimentos e exames, bem como esclarecer as dúvidas que emergem dos mesmos, transmite segurança e tranquilidade, propicia a sensação de respeito e valorização como coparticipante no cuidado. Por essa razão, enfatiza-se a necessidade de maior horizontalidade na relação estabelecida entre profissional de enfermagem e família, apreciando também o conhecimento expresso pelo familiar cuidador, pois, a partir do mesmo, torna-se possível atentar para as especificidades de cada criança e família.

Considerando que a hospitalização da criança pode gerar mudanças na rotina e na relação familiar, muitas vezes, a família confere à enfermagem o papel de referência e apoio, inclusive, associando-a à figura familiar. Assim sendo, os profissionais de enfermagem se encontram em lugar privilegiado para transformar o cuidado, valorizando o protagonismo dos familiares e contribuindo para que o cuidado compartilhado entre enfermagem e família se efetive, de forma respeitável, responsável e ética.

Este estudo registra como limitação a necessidade de ampliação do debate sobre a temática de cuidado compartilhado, já que o mesmo foi realizado em dois hospitais universitários do Sul do Brasil, assim representando as relações existentes em âmbito local. Além disso, faz-se imperativo que estudos futuros utilizem a técnica de pesquisa convergente assistencial no sentido de construção do cuidado compartilhado autêntico, uma vez que as ações de assistência vão sendo incorporadas no processo de pesquisa e vice-versa, contribuindo para a proposição de modelos de cuidado.

\section{REFERÊNCIAS}

1. Chagas MCS, Gomes GC, Pereira FW, Diel PKV, Farias DHR. Significado atribuído pela família ao cuidado da criança hospitalizada. Av Enferm [Internet]. 2017 [acesso em 2017 jun 26];35(1):7-18. Disponível em: http://revistas.unal.edu.co/index.php/avenferm/article/view/42466/59668.

2. Melo EMOP, Ferreira PL, Lima RAG, Mello DF. Envolvimento dos pais nos cuidados de saúde de crianças hospitalizadas. Rev Latinoam Enferm [Internet]. 2014 [acesso em 2017 abr 27]; 22(3):432-9. Disponível em: http://www.revistas.usp.br/rlae/article/view/86596/89502.

3. Ribeiro JP, Gomes GC, Silva PA, Thofehrn MA, Oliveira AMN, Tarouco ACMB. Refletindo acerca da construção do cuidado em pediatria. Rev Enferm UFPE [Internet]. 2016 [acesso em 


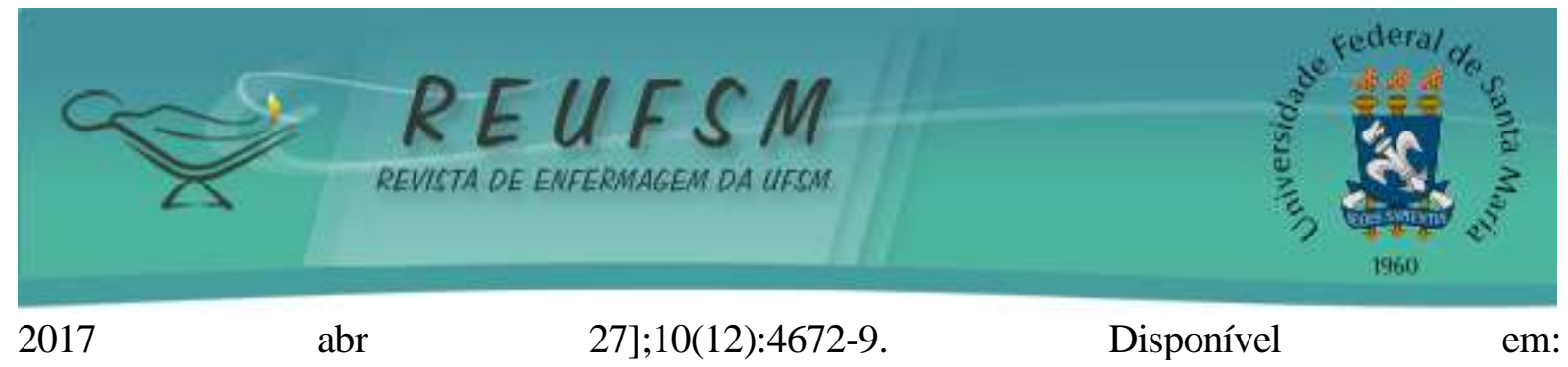

http://www.revista.ufpe.br/revistaenfermagem/index.php/revista/article/viewFile/9079/pdf_1904.

4. Romaniuk D, O'Mara L, Akhtar-Danesh N. Are parents doing what they want to do? Congruency between parents' actual and desired participation in the care of their hospitalized child. Issues Compr Pediatr Nurs [Internet]. 2014 [acesso em 2017 jun 26];37(2):103-21. Disponível em: http://www.tandfonline.com/doi/full/10.3109/01460862.2014.880532?scroll=top\&needAccess=true.

5. Pinto MCM, Camata DG, Oliveira AC, Dalge DP, Paes AT. Significado do cuidar da criança e a percepção da família para a equipe de enfermagem. Einstein [Internet]. 2009 [acesso em 2017 abr 27];7(1 Pt 1):18-23. Disponível em: http://apps.einstein.br/revista/arquivos/PDF/1037-einsteinv7n1p18_23.pdf.

6. Bedells E, Bevan A. Roles of nurses and parents caring for hospitalised children. Nurs Child Young People [Internet]. 2016 [acesso em 2017 jun 26];28(2):24-8. Disponível em: http://journals.rcni.com/doi/pdfplus/10.7748/ncyp.28.2.24.s22.

7. Flick W. Qualidade na pesquisa qualitativa. Porto Alegre: Artmed; 2009.

8. Guizzo BS, Krziminski CO, Oliveira DLLC. O software QSR NVIVO 2.0 na análise qualitativa de dados: ferramenta para a pesquisa em ciências humanas e da saúde. Rev Gaúcha Enferm [Internet]. 2003 [acesso em 2016 jun 26];24(1):53-60. Disponível em: http://seer.ufrgs.br/RevistaGauchadeEnfermagem/article/view/4437.

9. Minayo MCS. O desafio do conhecimento: pesquisa qualitativa em saúde. São Paulo: Hucitec; 2007.

10. Brasil. Ministério da Saúde. Conselho Nacional de Saúde. Resolução CNS nº66, de 12 de dezembro de 2012. Aprova as seguintes diretrizes e normas técnicas regulamentadoras de pesquisas envolvendo seres humanos. Brasília; 2012.

11. Gomes GC, Leite FLLM, Souza NZ, Xavier DM, Cunha JC, Pasini D. Estratégias utilizadas pela família para cuidar a criança no hospital. Rev Eletrônica Enferm [Internet]. 2014 [acesso em 2016 jun 26];16(2):434-42. Disponível em: https://www.fen.ufg.br/fen_revista/v16/n2/pdf/v16n2a21.pdf.

12. Gomes GC, Xavier DM, Pintanel AC, Farias DHR, Lunardi VL, Aquino DR. Significados atribuídos por familiares na pediatria acerca de suas interações com os profissionais da enfermagem. Rev Esc Enferm USP [Internet]. 2015 [acesso em 2017 jun 26];49(6):953-9. Disponível em: http://www.scielo.br/pdf/reeusp/v49n6/pt_0080-6234-reeusp-49-06-0953.pdf.

13. Marcinowicz L, Abramowicz P, Zarzycka D, Abramowicz M, Konstantynowicz J. How hospitalized children and parents perceive nurses and hospital amenities: a qualitative descriptive study in Poland. J Child Health Care [Internet]. 2016 [acesso em 2017 jun 26];20(1):120-8. Disponível em: http://journals.sagepub.com/doi/pdf/10.1177/1367493514551313.

14. Marques CDC, Lima MF, Malaquias TSM, Waidman MAP, Higarashi IH. O cuidador familiar da criança hospitalizada na visão da equipe de enfermagem. Cienc Cuid Saúde [Internet]. 2014 [acesso em 2016 jun 26];13(3):541-8.Disponível em: http://www.periodicos.uem.br/ojs/index.php/CiencCuidSaude/article/viewFile/22133/pdf_227 


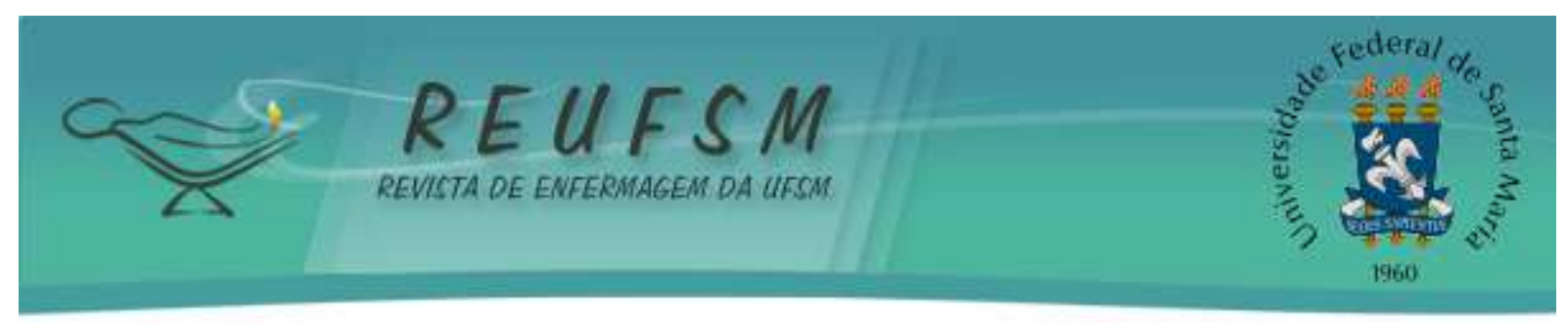

15. Giambra BK, Broome ME, Sabourin T, Buelow J, Stiffler D. Integration of parent and nurse perspectives of communication to plan care for technology dependent children: the theory of shared communication. J Pediatr Nurs [Internet]. 2017 [acesso em 2017 jun 26];34:29-35. Disponível em: http://www.pediatricnursing.org/article/S0882-5963(16)302330/fulltext.

16. Gabarra LM, Crepaldi MA. A comunicação médico-paciente pediátrico-família na perspectiva da criança. Psicol Argum [Internet]. 2011 [acesso em 2017 abr 27];29(65):209-18. Disponível em: http://132.248.9.34/hevila/Psicologiaargumento/2011/vol29/no65/7.pdf.

Data de submissão: 26/03/2017

Data de aceite: $24 / 08 / 2017$

Autor principal: Juliane Portella Ribeiro

Endereço: Gomes Carneiro, $\mathrm{n}^{\circ} 1,2^{\circ}$ andar. Universidade Federal de Pelotas, Faculdade de Enfermagem - Centro, Pelotas - RS. CEP: 96010-610

Email: ju_ribeiro1985@hotmail.com 